Endocrinol. Japon. 1987, 34 (6), 903-909

\title{
Effects of Food Deprivation and High Fat Diet on Immunoreactive $\beta$-Endorphin Levels in Brain Regions of Zucker Rats
}

\author{
Satoru TSUJII, Yoshikatsu NAKAI, Junichi FUKATA, Shigeo NAKAISHI \\ Hideo TAKAHASHI, TAKESHi USUI AND Hiroo IMURA
}

\author{
Second Division, Department of Internal Medicine \\ Faculty of Medicine, Kyoto University, \\ Kyoto 606, Japan
}

\begin{abstract}
The levels of immunoreactive $\beta$-endorphin (ir- $\beta$-EP) were measured in the brain and pituitary of lean Zucker rats subjected to food deprivation for $72 \mathrm{~h}$ and to a high fat diet, and in fatty Zucker rats after food deprivation for $72 \mathrm{~h}$. Ir- $\beta$-EP was increased in the neurointermediate (NI-) pituitary lobe but reduced in the medulla-pons of fatty rats when compared to lean littermates fed ad libitum. Food deprivation decreased ir- $\beta$-EP in the cortex and medullapons of lean rats and in the cortex, midbrain and NI-pituitary of fatty rats. In contrast, ir- $\beta$-EP was increased in the anterior pituitary of lean rats and in the striatum of fatty rats after deprivation. The high fat diet produced a decrease in ir- $\beta$-EP in the cortex, midbrain and NI-pituitary with an increase in the striatum and hypothalamus of lean rats. These results suggest that the ir- $\beta$-EP concentration could be differentially affected in different brain regions of Zucker rats by changes in the energy balance.
\end{abstract}

There is body of literature which implicates the endogenous opioid system in the regulation of food intake and/or body weight (Morley et al., 1983; Reid, 1985; Sanger, 1981). Opioid agonists generally stimulate food intake, whereas opioid antagonists suppress ingestive behavior elicited by food deprivation and by the injection of 2-deoxy-D-glucose or opioid peptides. Food deprivation modified the endogenous opioid

Received April 3, 1987

Correspondence: YOSHIKATSU NAKAI, 2nd Division, Department of Internal Medicine, Kyoto University, 54 Shogoin Kawahara-cho, Sakyo-ku, Kyoto, 606, Japan system, in that fasting produced significant analgesia which could be blocked by naloxone (McGivern and Berston, 1980) and altered the opioid peptides concentration in the brain and pituitary (Gambert et al., 1980 ; Majeed et al., 1986; Morley et al., 1982; Reid et al., 1982; Vaswani and Tejwani, 1986). Equivocal changes are reported, however, concerning ir- $\beta$-endorphin or ir-dynorphin in the brain after food deprivation.

The endogenous opioid system seems to operate with a distinctly different tone in genetically obese rodents, such as obese mice (ob/ob) and fatty Zucker rats (fa/fa). 
Several reports indicate that opioid peptide levels are increased in the brain and/or pituitary of genetically obese mice and rats and that these animals are super-sensitive to opioid antagonists (Ferguson-Segall et al., 1982; Gibson et al., 1981; Margules et al., 1978; Recant et al., 1980 ; Rossier et al., 1979).

Morphine seems to lead to increased consumption of high fat diets (MarksKaufman, 1982), while naloxone decreased the intake of a highly palatable diet (Apfelbaum and Mandehoff, 1981; Mandehoff et al., 1982) and more effectively influenced the intake of fat component of a diet (Marks-Kaufman and Kanarek, 1981; Vaswani and Tejwani 1983). It is intriguing, therefore, to study the biochemical change in the endogenous opioid system during the intake of fat or palatable diets.

The present study was undertaken to evaluate the effect of food deprivation on the content of ir- $\beta$-endorphin (ir- $\beta$-EP) in discrete brain regions and pituitaries of lean and fatty Zucker rats, and to further investigate the effect of a high fat diet, as another dietary manipulation, on ir- $\beta$-EP in the brain and pituitary of lean rats.

\section{Materials and Methods}

Male lean $(\mathrm{Fa} /-)$ and fatty (fa/fa) Zucker rats, aged approximately 10 weeks, were housed 5 per cage and maintained on a standard laboratory diet ad libitum with a 12-hour light-dark cycle (lights on from $0700 \mathrm{~h}$ to $1900 \mathrm{~h}$ ). Water was always freely available. The animals were divided into 5 groups, each consisting of at least 8 animals: (1) a control lean littermate rat group which were continuously kept on a standard diet $(3.6 \mathrm{kcal} / \mathrm{g})$ containing $5.1 \%$ fat and $54.5 \%$ carbohydrate; (2) a lean littermate group which were deprived of food for $72 \mathrm{~h}$; (3) a lean littermate group which were given a high fat diet $(3.9 \mathrm{kcal} / \mathrm{g})$ for 7 days, composed of $44 \%$ sweetened condensed milk, $8 \%$ corn oil and $47 \%$ standard laboratory chow following the menu of Levin et al. (Levin et al., 1983), contain- ing $14.1 \%$ fat and $50 \%$ carbohydrate; (4) a group of fatty rats which were maintained on a standard diet (5) a group of fatty rats which were deprived of food for $72 \mathrm{~h}$. At the end of the experiment, the animals were decapitated between $1000 \mathrm{~h}$. and $1300 \mathrm{~h}$. The anterior (A-) and neuro-intermediate (NI-) pituitary lobes were rapidly removed, and the hypothalamus, striatum, midbrain, medulla-pons, hippocampus and cortex were dissected on ice by the method of Glowinski and Iversen (1966). The tissue were rapidly frozen on dry ice and stored at $-80^{\circ} \mathrm{C}$ until the time of assay.

The frozen samples were weighed and homogenized in acidified methanol $1: 1$ (mixture of absolute methanol and $0.1 \mathrm{~N} \mathrm{HCl}$ ) with a Palytron homogenizer, and then centrifuged at $15,000 \mathrm{~g}$ for $15 \mathrm{~min}$. Aliquots of the supernatant were neutralized with an equal volume of $0.1 \mathrm{~N} \mathrm{NaOH}$ and appropriate dilutions were assayed for ir- $\beta$-EP. The recovery for $\beta$-EP added before homogenization was computed to be approximately $66 \%$. Dilution curves for the tissue extract were parallel to those obtained with $\beta$-EP.

The $\beta$-EP radioimmunoassay (RIA) was performed according to the procedure previously described (Nakai et al., 1978). The antiserum recognizes $\beta$-EP and $\beta$-lipotropin to an equimolar degree but cross-reactions to $\alpha$ - and $\gamma$-endorphin, dynorphin, and enkephalins as well as other peptides were negligible.

Data were statistically evaluated by the analysis of variance (One-way ANOVA) for the comparison of 5 experimental groups in each brain region and pituitary and, if indicated, further comparison between individual groups was performed by Duncan's new multiple range test.

\section{Results}

Food deprivation for $72 \mathrm{~h}$ reduced the body weight of lean Zucker rats by $18 \%(238.2 \pm 11.3$ to $194.4 \pm 9.8 \mathrm{~g})$ and that fatty Zucker rats by $16 \%(341.8 \% \pm 8.3$ to $287.2 \pm 7.9 \mathrm{~g})$. There was no significant difference between the body weight of the lean control group $(236 \pm 13.4 \mathrm{~g})$ and highfat-diet group $(242.4 \pm 8.4 \mathrm{~g})$ at the time of sacrifice. 


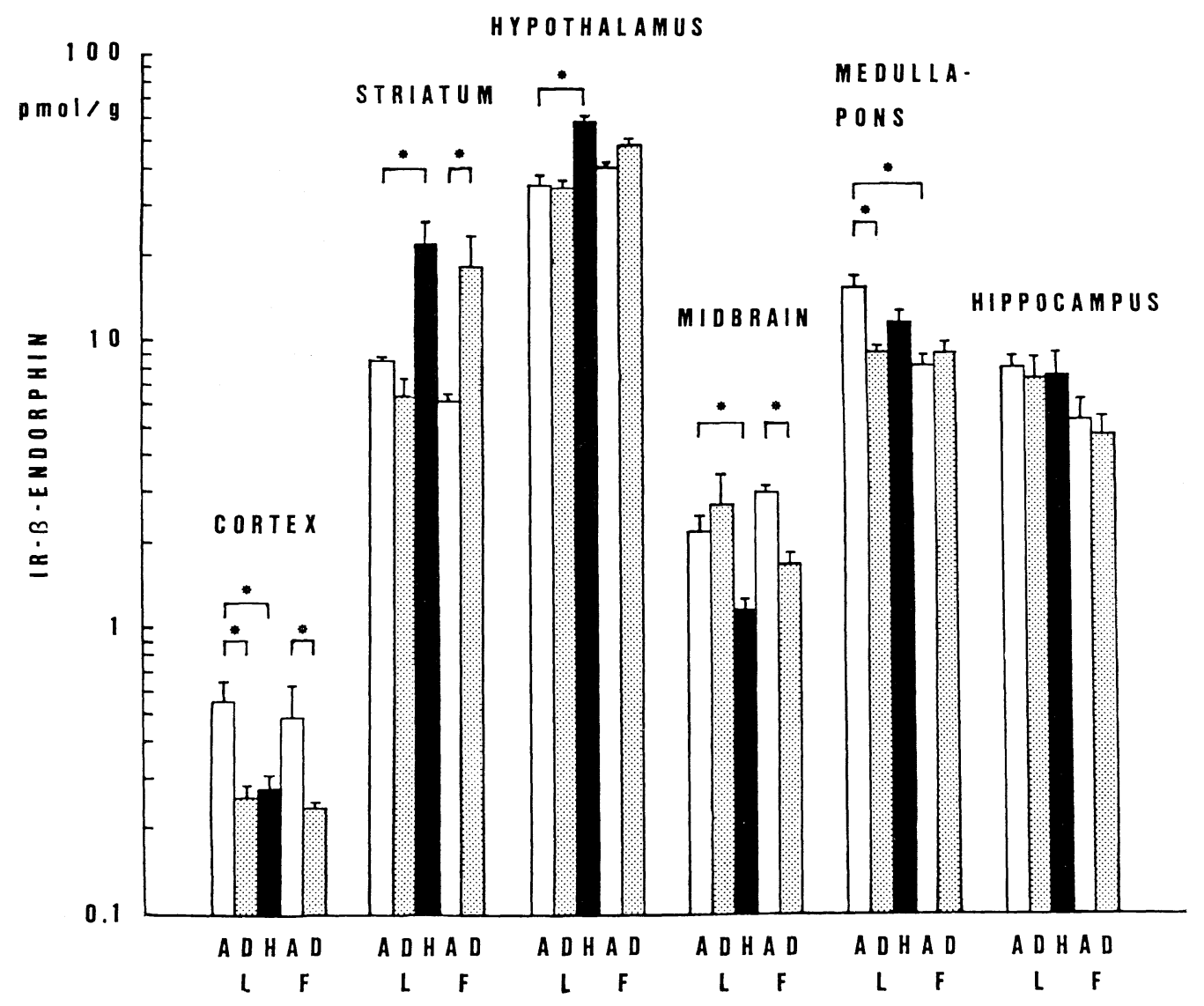

Fig. 1. Effect of food deprivation or a high fat diet on ir- $\beta$-EP concentrations in brain regions of lean and fatty rats. Values are expressed as means \pm S. E. M. (pmol/g wet tissues) for at least 8 animals per group. $\mathrm{L}=$ lean rats; $\mathrm{F}=$ fatty rats; $\mathrm{A}=$ fed laboratory chow ad libitum; $\mathbf{D}=$ deprived of food; $\mathrm{H}=$ fed a high fat diet. Data were analyzed by ANOVA and Duncan's new multiple range test. $* \mathrm{p}<0.01$.

One-way ANOVA showed a significant effect of treatment on ir- $\beta$-EP in the cortex $(\mathrm{F}(4,35)=6.15, \mathrm{p}<0.01)$, striatum $(\mathrm{F}(4,35)$ $=4.58, \mathrm{p}<0.01)$, hypothalamus $(\mathrm{F}(4,38)=$ $11.88, \mathrm{p}<0.01)$, midbrain $(\mathrm{F}(4,35)=3.65$, $\mathrm{p}<0.05)$, medulla-pons $(\mathrm{F}(4,35)=5.73, \mathrm{p}<$ $0.01)$, and $\mathrm{A}-(\mathrm{F}(4,36)=3.36, \mathrm{p}<0.05)$ and NI-pituitary $(\mathrm{F}(4,38)=20.28, \mathrm{p}<0.01)($ Fig. 1 and 2). Fatty rats had much more ir- $\beta$ EP in the NI-pituitary but less in the medulla-pons than lean counterparts, when fed a standard diet ad libitum. Food deprivation significantly reduced ir- $\beta$-EP in the cortex and medulla-pons of lean rats, and in the cortex, midbrain and NI-pituitary of fatty rats. On the other hand, ir- $\beta$-EP was increased in the A-pituitary of lean rats and in the striatum of fatty rats after food deprivation. Lean rats fed a high fat diet had much less ir- $\beta$-EP in the cortex, midbrain and NI-pituitary but more in the striatum and hypothalamus than lean controls. 


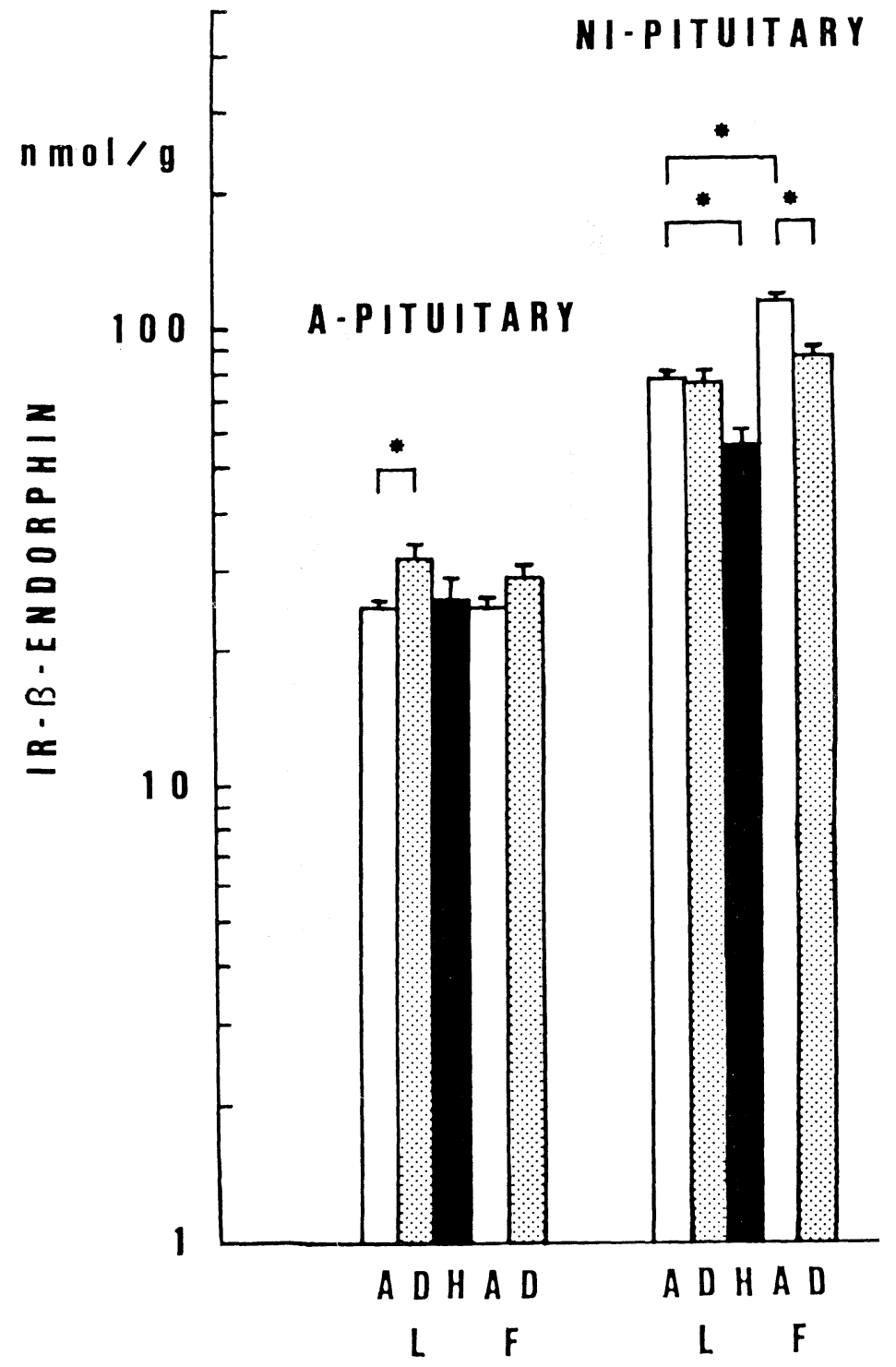

Fig. 2. Effect of food deprivation or a high fat diet on ir- $\beta$-EP concentrations in the pituitary of lean and fatty rats. Values are expressed as mean \pm S. E. M. (nmol/g wet tissue) for at least 8 animals per group. Data were analyzed by ANOVA and Duncan's test. $* \mathrm{p}<0.01$. Abbreviations are the same as in Fig. 1.

\section{Discussion}

The present results are consistent with previous reports in that higher levels of ir$\beta$-EP were observed in the NI-pituitary of fatty rats (Gibson et al., 1981; Margules et $a l ., 1978)$. There was no difference in the amount of ir- $\beta$-EP in brain regions, except in the medulla-pons, in lean and fatty rats fed ad libitum. To explain the difference in the medulla-pons in the two phenotypes, we might have to take into account a possible role of a $\beta$-EP-synthesizing cell group in the nucleus tractus solitarius (Khachaturian et al., 1985). The endogenous 
opioid system is presumed to be a division of the autonomic nervous system or to modulate it (Margules, 1979).

Fasting could affect the ir- $\beta$-EP content in the brain. The present results showed that food deprivation decreased ir- $\beta$-EP in the cortex and medulla-pons of lean rats and in the cortex, midbrain and NI-pituitary of fatty rats. In contrast, ir- $\beta$-EP was increased in the anterior pituitary of lean rats and in the striatum of fatty rats after deprivation. These changes may be related to stressful conditions caused by starvation, under which genotype differences in ir- $\beta$-EP were observed. The genotypic difference is probably in part due to the increased amount of fat and/or glycogen available for metabolism in fatty rats even after food deprivation. As another way of changing the opioid peptide concentration, Carr and Simon (1984) have suggested that food deprivation potentiates an ingestive reward and that potentiation is mediated by the endogenous opioid system.

The present results showed that the high fat diet had a greater effect on the amount of ir- $\beta-E P$, but this differed according to the brain regions. The pattern of changes in the ir- $\beta$-EP concentration in lean rats on a high fat diet is similar to that in fatty rats with food deprivation. This may simply indicate that lean rats on a high fat diet were under conditions similar to fatty rats deprived of foods; i. e., stressful conditions or metabolic circumstances consequent on a high fat diet in lean rats that are characterized by hyperinsulinemia and hypoglucagonemia associated with hyperlipidemia and ketonemia (Nosadini, 1980), which persist in fatty rats even after fasting (Triscari, 1980). If the sensory qualities of the food provided a natural reward for maintaining ingestion (Reid, 1985), the endogenous opioid system may contribute to increased preference for fat or sweetness (sucrose is a major ingredient as a carbohydrate in our high fat diet).
It is now uncertain whether the increase in the ir- $\beta$-EP concentration in the hypothalamus and striatum is due to an increase in biosynthesis or a reduction in secretion. The present finding that ir- $\beta$-EP was increased in some regions but decreased in others may reflect a facilitation of the $\beta$-endorphinergic system when fed a high fat diet. The brain sites where opiates induce a reward are a matter of controversy with the exception of the ventral tegmental area in the midbrain (Hoebel, 1985). With regard to the incentive reward, the dopaminergic system seems to play an important role (Hoebel, 1985 ; Reid, 1985). The $\beta$-endorphinergic system is likely to modulate or interact with the dopaminergic system (Kalivas, 1985). Further investigation is required to determine the exact relationship between $\beta$-EP-containing neurons and dopaminergic neurons.

Dietary obese rats given a high carbohydrate diet have increased ir- $\beta$-EP in the pituitary (Gunion and Peters, 1981). The short-term feeding with a high fat diet reduced ir- $\beta$-EP in the NI-pituitary. It is unclear whether difference is due to a high fat diet that is given instead of a high carbohydrate diet. Increased secretion of $\beta$-EP or $\beta$-lipotropin may modulate the metabolic processing of fat or sucrose directly or indirectly involving pancreatic hormones (Reid and Yen, 1981).

The present results suggest that different brain regions could exhibit different changes in $i r-\beta$-EP responding to altered energy balance, though the underlying mechanism is unknown. For further clarification of the role that the endogenous opioid system plays in the regulation of energy balance, studies on the interaction of three opioid systems with other neurotransmitters or neuromodulators in intra- and extrahypothalamic areas, especially with the dopaminergic system. 


\section{References}

Apfelbaum, M. and A. Mandehoff (1981). Naltrexone suppresses hyperphagia induced in the rat by a highly palatable diet. Pharmacol. Biochem. Behav. 15, 89-91.

Carr, K. D. and E. J. Simon (1984). Potentiation of reward by hunger is opioid mediated. Brain Res. 297, 369-373.

Ferguson-Segall, M., J. J. Flynn, J. Walker and D. L. Margules (1982). Increased immunoreactive dynorphin and leuk-enkephalin in posterior pituitary of obese mice (ob/ob) and supersensitivity to drugs that act at kappareceptors. Life Sci. 31, 2233-2236.

Gambert, S. R., T. L. Garthwaite, C. H. Pontzer and T. C. Hagen (1980). Fasting associated with decrease in hypothalamic beta-endorphin. Science 210, 1271-1272.

Gibson, M. J., A. S. Liotta and D. T. Krieger (1981). The Zucker fa/fa rat: Absent circadian corticosterone periodicity and elevated $\beta$ endorphin concentrations in brain and neurointermediate pituitary. Neuropeptides 1, 349362.

Glowinski, J. and L. L. Iversen (1966). Regional studies of catecholamines in rat brain. 1. The disposition of $\left[{ }^{3} \mathrm{H}\right]$-norepinephrine, $\left[{ }^{3} \mathrm{H}\right]$-dopamine and $\left[{ }^{3} \mathrm{H}\right]$-DOPA in various regions of the brain. J. Neurochem. 13, 655-669.

Gunion, M. W. and R. H. Peters (1981). Pituitary $\beta$-endorphin, naloxone and feeding in several experimental obesities. Am. J. Physiol. 241, R173-R184.

Hoebel, B.G. (1985). Brain neurotransmitters in food and drug reward. Am. J. Clin. Nutr. 42, 1133-1150.

Kalivas, P. W. (1985). Interactions between neuropeptides and dopamine neurons in the ventromedial mesencephalon. Neurosci. Biobehav. Rev. 9, 573-586.

Khachaturian, H., M. E. Lewis, M. K-H. Schafer and S. J. Watson (1985). Anatamy of the CNS opioid system. Trends Neurosci. 8, 111-119.

Levin, B. E., J. Triscari and A. C. Sullivan (1983). Altered sympathetic activity during development of diet-induced obesity in the rat. Am. J. Physiol. 244, R347-R355.

Majeed, N. H., W. Lason, B. Przewlocka and R. Przewlocki (1986). Brain and peripheral opioid peptides after changes in ingestive behavior. Neuroendocrinology 42, 267-272.
Mandehoff, A., F : Fumeron, M. Apfelbaum and D. L. Margules (1982). Endogenous opiates and energy balance. Science 215, 1536-1538.

Margules, D. L., B. Moisset, M. J. Lewis, H. Shibuya and C. B. Pert (1978). $\beta$-endorphin is associated with overeating in genetically obese mice $(\mathrm{ob} / \mathrm{ob})$ and rats $(\mathrm{fa} / \mathrm{fa})$. Science 202, 988-991.

Margules, D. L. (1979). Beta-endorphin and endoloxone: Hormones of the autonomic nervous system for the conservation or expenditure of bodily resources and energy in anticipation of famine or feast. Neurosci Biobehav. Rev. 3, 155-162.

Marks-Kaufman, R. and R. B. Kanarek (1981). Modificiations of nutrient selection induced by naloxone in rats. Psychopharmacology 74, 321324.

Marks-Kaufman, R. (1982). Increased fat consumption induced by morphine administration in rats. Pharmacol. Biochem. Behav. 16, 949955.

McGivern, R. F. and G. B. Berston (1980). Mediatian of diurnal fluctuations in pain sensitivity in the rat by food intake patterns: reversal by naloxone. Science 210, 210-211.

Morley, J. E., M. K. Elson, A. S. Levine and R. B. Shafer (1982). The effects of stress on central nervous system concentrations of the opioid peptide, dynorphin. Peptides 3, 901906.

Morley, J. E., A. S. Levine, G. K. Yim and M. T. Lowy (1983). Opioid modulation of appetide. Neurosci. Biobehav. Rev. 7, 281-305.

Nakai, Y., K. Nakao, S. Oki, H. Imura and C. H. Li. (1978). Presence of immunoreactive $\beta$-endorphin in plasma of patients with Nelson's syndrome and Addison's disease. Life Sci. 23, 2293-2298.

Nosadini, R., F. Ursini, P. Tessari, M. C. Garotti, F. De Biasi and A. Tiengo (1980). Hormonal and metabolic characteristics of genetically obese Zucker and dietary obese Spargue-Dawley rats. Eur. J. Clin. Invent. 10, 113-118.

Recant, L., N. R. Voyles, M. Luciano and C. B. Pert (1980). Naltrexone reduced weight gain, alters " $\beta$-endorphin", and reduces insulin output from pancreatic islets of genetically obese mice. Reptides 1, 309-313.

Reid, L. D., A. M. Konecka, R. Prezwlocki, M. H. Millan, M. J. Millan, and A. Herz (1982). Endogenous opioides, circadian rhythms, 
nutrient deprivation, eating and drinking. Life Sci. 31, 1829-1832.

Reid, L. D. (1985). Endogenous opioid peptides and regulation of drinking and feeding. Am. J. Clin. Nutr. 42, 1099-1132.

Reid, R. L. and S. S. C. Yen (1981). $\beta$ endorphin stimulates the secretion of insulin and glucagon in humans. J. Clin. Endocrinol. Metab. 52, 592-594.

Rossier, J. J. Rogers, T. Shibasaki, R. Guillemin and F. Bloom (1979). Opioid peptides and $\alpha$-melanocyte-stimulating hormone in genetically obese (ob/ob) mice during development. Proc. Natl. Acad. Sci. U.S.A. 76, 2077-2080.

Sanger, D. J. (1981). Endorphinergic mechanism in the control of food and water intake. Appetite 2, 193-208.

Triscari, J., G. [F. Bryce and A. C. Sullivan (1980). Metabolic consequences of fasting in old lean and obese Zucker rats. Metabolism 29, 377-385.

Vaswani, K. K., G. A. Tejwani and S. Mousa (1983). Stress induced differential intake of various diets and water by rat: the role of opiate system. Life. Sci. 32, 1983-1996.

Vaswani, K. K. and G. A. Tejwani (1986). Food deprivation-induced changes in the level of opioid peptides in the pituitary and brain of rat. Life Sci. 38, 197-201. 